\title{
Communal Responsibility: a History of Health Collectives in Australia
}

Matthew P Grant (1,2,3,4), Jennifer AM Philip (1,2), Luc Deliens (3), Paul A Komesaroff (4)

(1) VCCC Palliative Medicine Research Group

(2) Department of Palliative Medicine, St Vincent's Hospital Melbourne

(3) End of Life Care Research Group, Belgium

(4) School of Primary and Allied Health Care, Monash University

\section{Word Count:}

- Abstract - 62 words

- Article - 2000 words

- $\quad$ References - 16

\begin{abstract}
Health care encompasses multiple discourses to which health professionals, researchers, patients, carers and lay individuals contribute. Networks of patients and non-professionals often act collectively to build capacity, enhance access to resources, develop understanding and improving provision of care. This article explores the concept of health collectives and three notable examples that have had an enduring and profound impact in the Australian context.
\end{abstract}

Key Words: communities, informal caregivers, support groups, patient groups, HIV, parent groups, cancer groups

Acknowledgements: Matthew Grant would like to acknowledge the NHMRC postgraduate scholarship, which supported this work.

Corresponding Author: Matthew Grant

VCCC Palliative Medicine Research Group

This is the author manuscript accepted for publication and has undergone full peer review but has not been through the copyediting, typesetting, pagination and proofreading process, which may lead to differences between this version and the Version of Record. Please cite this article as doi: 10.1111/imj.14426 


\title{
Communal Responsibility: a History of Health Collectives in Australia
}

\author{
Matthew Grant, Jennifer Philip, Luc Deliens, Paul A. Komesaroff
}

The manner in which health care is provided in Australia has been shaped by professionals, patients, administrators and government. The public perception of care is predominantly determined by the structures and processes of the formal health system. Beneath this, however, are layers of informal health care provision, including family caregivers, parents nursing children, and everyday sharing of non-professional advice. Professionals and academics frequently lead public discourse regarding health care, in the media or with government. The experiences of patients and the complexity of the networks of participants that stand behind and extend beyond professional led health provision receives minimal exposure (1).

The role played by informal health providers is already great but is likely to increase rapidly. Australia has an aging population with rising rates of chronic diseases, and to meet these future challenges massive support external to the formal health system will be required that incorporates non-professional participation and responsibility (2). The aim of this paper is to formulate the

This article is protected by copyright. All rights reserved. 
concept of the 'health collective', to describe and explore its key role in the provision of health care, and to offer an understanding of its significance, potential and complexities.

\section{Defining health collectives}

It is becoming increasingly recognised that non-professionals are important components of care networks and are not simply passive recipients of health care (2). While the current popular concern with 'person centred care' recognises the importance of individual patients as the focus of care, a role for other non-professionals as providers of care is less explicit (3). However, patients and carers do actively participate in advocacy, awareness campaigns and direct provision of support and expertise. Health professionals are trained to engage with illness in relation to frameworks arising from science and its concepts of causality. Patients encounter the same phenomena through the lenses of their personal impact, illness and disability. Accordingly, a single illness may produce contrasting understandings among the different participants. This may generate opposing narratives with divergent meanings and different interpretations of the outcomes (1). While this complexity may occasionally prove challenging to health practitioners, inclusion of the perspectives and experiences of patients may offer considerable benefits to patients and improved outcomes for the health system (4).

It is important to acknowledge that patients do not experience their illnesses in isolation. Though it is not well recognised, narratives of illness are widely disseminated and shared within hospitals, waiting rooms, existing social structures, and through social and internet media (1). The relationships formed between patients and other interested individuals constitute active

This article is protected by copyright. All rights reserved. 
communities that may play important, sometimes decisive, roles in relation to health care outcomes (4). Such communities may vary markedly in terms of whom they comprise, their temporality, their formal structures and their specified aims. Nonetheless, despite this variety, they serve a common, constant function by providing forums through which shared understandings and identities are constructed and collective actions in response to specific health issues are developed (4). While the existence of such communities is not a new phenomenon, their roles and impact have been poorly appreciated.

We propose to refer to these groups broadly by the term 'health collectives', which we employ to include structured communities external to the formal health system, comprised primarily of patients and non-professionals. The most easily recognisable health collectives are those that work in parallel with the formal health system: for example, Alcoholics Anonymous and cancer support groups. But there are many other collectives that are less formalised and which interact with each other and the health system in multiple ways, including via a range of electronic media, may involve little or no face to face contact, and may engage in activities, such as policy, fund-raising and research, that extend beyond internal support (4).

Three examples of health collectives will be described that have had a profound effect on health care in Australia.

\section{Cancer Support Groups}

This article is protected by copyright. All rights reserved. 
Cancer support groups in their current form are a relatively recent phenomenon. The pioneering group in the cancer field was 'Reach to Recovery', founded in 1954 in the USA by Terese Lasser in response to a lack of support following her mastectomy for breast cancer (5). It was originally a patient-led collective focusing on post-mastectomy rehabilitation and support. Owing to its success, in 1969 'Reach to Recovery' became incorporated into the American Cancer Society, formalising the program and placing it under the auspices of professional leadership (6). In response to this reduced control over group processes and purpose, many breast cancer patients initiated their own communities. These ensuing groups focused on community level information, emotional support, and wider activism, encouraging women who choose to question their 'passive' role within the doctor-patient relationship where mastectomy was the singular surgical treatment for breast cancer (7) (6). The advocacy of these groups was instrumental in the development of breast conserving techniques, and advancing lymphoedema management (6).

There is little documented evidence of Australian health collectives for cancer until the decade following 1980 . These initial groups were small self-formed communities of cancer patients aiming to share information and provide mutual support, primarily initiated by those experiencing breast or prostate cancer. As these collectives became more widespread, networks were formed to create avenues between groups for advocacy and dissemination of knowledge, culminating in groups such as the Prostate Cancer Foundation of Australia (1996) and Breast Cancer Network Australia (1998) (8). The past two decades have seen a proliferation of collectives across all types of cancer: from patient-driven mutual support groups to large-scale networks of consumers who are prominent advocates in research and health policy. 


\section{Parent groups}

Parent groups form an integral component of post-partum care in Australia, which is one of the few countries where such groups exist as part of routine care. They represent a unique phenomenon which emerged from collective action by new mothers to become incorporated into the formal health system. In their present form these groups are initiated by the local health system but continue beyond this involvement, and remain participant controlled.

The decade of 1940 saw a shift in a series of medical and social factors surrounding childbirth (9). The infant mortality rate had improved vastly over previous decades, an influx of post-war migration and increased mobility, with young families often isolated from traditional social supports (10). Birth practices shifted, with the majority of births occurring in the hospital setting, and support in the post-partum period became specialised and short in duration (11). New mothers with limited family supports started forming their own communities in New South Wales, often meeting in the waiting rooms of local infant welfare centres or making contact through community notice boards. These groups served as forums to share information and frustrations, for support, and an environment that accepted infants and breastfeeding (9). In 1963, some Sydney-based centres started formally organising these 'mothercraft groups', combining education sessions facilitated by midwives with communities of new mothers who were able to set their own directions and activities (9). These groups were an immediate success and spread rapidly to become a routine component of post-partum care. They have, in succeeding years been re-named 'parent groups' in recognition of the important involvement of partners in raising infants and supporting mothers. 
In 1964, one such parent collective in Melbourne became increasingly interested in breastfeeding. At this time breastfeeding rates were low, with just $20 \%$ of mothers feeding at three months, and recommendations for breastfeeding were highly regimented (12). What was originally structured as a peer support and education network evolved over the coming decade into a broad movement focusing on support, information and national advocacy for breast-feeding. This formed the basis for what eventually in term became the Australian Breastfeeding Association, an organisation which has been instrumental in promoting breastfeeding as an aspect of normal carewith current rates of $70 \%$ at 3 months-adaptive to the needs of mothers and children.

\section{HIV collectives}

Australia is one of the few countries that can claim success in effectively limiting the early spread of HIV transmission (13). Following an early peak in 1984, the rates of new HIV infections declined for the next decade, prior to the institution of government health policy interventions in mid-1985, (13). As the cohort most affected, the gay community was at the forefront of the response to HIV and played a key role both in organising the community response and directing the formulation and implementation of public policy.

After the first Australian case of HIV in late 1982, early the following year a number of informal public forums were organised by members of the gay community to promote understanding of HIV and of safe-sex as a preventive measure. From these forums, the NSW AIDS Action Committee and the Alternative Lifestyle Organisation (ALSO) arose (14). These communities

This article is protected by copyright. All rights reserved. 
quickly demonstrated a willingness and capacity to engage with experts from within the formal health systems to promote their objectives:

"Basically we were able to draw together very quickly a nucleus of very intelligent, articulate and committed, passionate people, men and women, who had experience in the law, in health, in social marketing and advertising, political activism, community organisation, psychology and medicine."(15)

HIV collectives were formed from within existing gay communities, promoting immediate and active strategies to address HIV as a health issue. They worked together with community groups, health systems and government organisations with a range of purposes: to educate those at risk (especially around safe sex practices), to disseminate new research, to advocate for public awareness and reduce stigmatisation of HIV, and to influence health policy (13). In an analysis of the Australian response to HIV, Plummer concludes that "grassroots and informal activities were vital to Australia's early and effective response to AIDs... [including] community mobilisation and the timely intervention of front-line clinical services alerted by early reports in the press, and activism in the gay community.(13) p.792)"

During this period, homosexual intercourse continued to be illegal in some States, and the appearance of HIV exacerbated a pre-existing negative public perception of homosexuality. Individuals with HIV were often disconnected from their families and more orthodox social networks. Their systems of support were frequently grounded within the gay community and became of increasing importance as people navigated the terminal stages of their disease. Small

This article is protected by copyright. All rights reserved. 
collectives developed to provide care for those dying from HIV, comprised of volunteers, friends, and members of the gay community, to provide support of all kinds, including allowing them to live and die at home (16).

"We went in and did all the cleaning up, whether people had soiled themselves or vomited... When people did have friends and family around to support them, it meant that we could do all of those mundane but exhausting things, so loved ones could have quality time and offer emotional support" (16).

As HIV became a chronic illness, for the most part these communities dissolved. Other groups, such as the Bobby Goldsmith Foundation, have evolved from a collective focused on providing care, towards HIV advocacy and education.

\section{Implications}

The three collectives associated with these examples have had profound effects on health care in Australia, constituting substantial networks of informal care-that is, outside the boundaries of the institutions of the conventional health care system. All have represented a response to, and arisen out of the knowledge of, experiences of change in health status at the community level. The outcomes health collectives generate are complex and sometimes radical, ranging from direct contributions to daily care, to precipitating changes in social policy, to challenging extant medical frameworks of interpreting illness. Often, their democratic roots and organisation have supported ongoing, fertile public debates and the emergence of alternative viewpoints, which have sometimes eventually been incorporated into the mainstream. 
This paper has focused on an illustrative overview to foster an appreciation of the wider roles and implications of health collectives. We suggest that their importance justifies further detailed study, covering their internal structures and dynamics, to examine how their promise may be mobilised more systematically in the service of community-based health care. If this proves to be possible, health collectives may contribute to a more differentiated, responsive, democratic and cost-effective health care system.

1. Timmermans $\mathrm{S}, \mathrm{Oh} \mathrm{H}$. The continued social transformation of the medical profession. Journal of health and social behavior. 2010;51(1_suppl):S94-S106.

2. Kellehear A. Compassionate cities: Routledge; 2012.

3. Richards T, Coulter A, Wicks P. Time to deliver patient centred care. BMJ : British Medical Journal. 2015;350:h530.

4. Brown P, Zavestoski S. Social movements in health: an introduction. Sociol Health Illn. 2004;26(6):679-94

5. Cantor D. Before Survivorship: The Moment of Recovery in Twentieth-century American Cancer Campaigns. Social History of Medicine. 2014;27(3):440-65.

6. Osuch JR, Silk K, Price C, Barlow J, Miller K, Hernick A, et al. A Historical Perspective on Breast Cancer Activism in the United States: From Education and Support to Partnership in Scientific Research. J Womens Health (Larchmt). 2012;21(3):355-62. 
7. Borkman T. Understanding self-help/mutual aid: Experiential learning in the commons: Rutgers University Press; 1999.

8. Grassi L, Riba M. Clinical psycho-oncology: an international perspective: John Wiley \& Sons; 2012.

9. O'Connor K. Our Babies: The State's Best Asset: a History of 75 Years of Baby Health Services in New South Wales: NSW Department of Health; 1989.

10. Brown N. Governing Prosperity: Social change and social analysis in Australia in the 1950s: Cambridge University Press Cambridge; 1995.

11. Hodnett ED, Gates S, Hofmeyr GJ, Sakala C. Continuous support for women during childbirth. Cochrane Database of Systematic Reviews. 2007(3).

12. Karen Twigg JB. "Mother to Mother": Mary Paton's Leadership in the Nursing Mother's Association of Australia, 1964-1975. In: Francis RG, Patricia; and Standish, Ann, editor. Seizing the Initiative: Australian Women Leaders in Politics, Workplaces and Communities. Melbourne: The University of Melbourne; eScholarship Research Centre; 2012.

13. Plummer D, Irwin L. Grassroots activities, national initiatives and HIV prevention: clues to explain Australia's dramatic early success in controlling the HIV epidemic. International journal of STD \& AIDS. 2006;17(12):787-93.

14. Bowtell W. Australia's response to HIV/AIDS 1982-2005. Lowy Institute for International Policy. 2005.

15. Council VA. On Australian Shores [Available from: http://undertheredribbon.com.au/ourstory/1983-1987/on-australian-shores/.

16. Wiseman H. 10 minutes with Mike Kennedy: Palliative Care Australia; 2015 [Available from: http://palliativecare.org.au/palliative-matters/10-minutes-with-mike-kennedy/.

This article is protected by copyright. All rights reserved. 


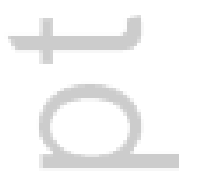

This article is protected by copyright. All rights reserved. 


\section{University Library}

\section{- M M N E R VA A gateway to Melbourne's research publications}

Minerva Access is the Institutional Repository of The University of Melbourne

Author/s:

Grant, MP;Philip, JAM;Deliens, L;Komesaroff, PA

Title:

Communal responsibility: a history of health collectives in Australia

Date:

2019-09-01

Citation:

Grant, M. P., Philip, J. A. M., Deliens, L. \& Komesaroff, P. A. (2019). Communal responsibility: a history of health collectives in Australia. INTERNAL MEDICINE JOURNAL, 49 (9), pp.1177-1180. https://doi.org/10.1111/imj.14426.

Persistent Link:

http://hdl.handle.net/11343/286355 